\title{
STANDARDIZED WOODEN SYSTEM FOR TIMBER INTERNAL TENSION SIMULATION
}

\author{
Francesco Sforza ${ }^{1}$, Luca Marchi ${ }^{1}$, Stefano Grigolato ${ }^{1}$, Gianluca Cucchi ${ }^{2}$ \\ ${ }^{1}$ University of Padova, Italy; ${ }^{2}$ Istruttori Forestali Lombardi, Italy \\ francesco.sforza@unipd.it, luca.marchi@unipd.it, stefano.grigolato@unipd.it, info@isfol.org
}

\begin{abstract}
Forest operations performed after natural disturbances occurrence can be highly dangerous due to the critical environmental conditions. Only specialised operators can address such challenging situations. However, the high-quality training activities needed to train forestry operators are not easily feasible in real conditions. The implementation of an engineering system that simulates the complex context of salvage tasks can be a valid solution to prepare operators in a controlled environment. The simulation of critical issues in the use of damaged forest areas, typically represented by logs subjected to a typical stress situation, such as tensile or compressive stress levels, will be carried out through the design of a mobile system for simulation of tensions in timber. The proposed solution aims to define a modular wooden structure to be realized with standard logs available at the logging site to be versatile and safe. The structure will be provided with sensors and load cells that will show the exact level of the stress applied to the logs during the cutting simulation. To this aim, computer analyses with finite element models have been conducted to design a solution that considers multiple parameters, such as log dimensions, tree species, maximum load bearing capacity of the structure and defines an optimal range of design solutions. The numerical procedure recreates the actual stress level developed in collapsed trees, or other unfavourable situations, which might lead to unexpected hazardous condition for the forest operator. The obtained structure must fulfil different requirements: low weight structure, in order to keep the realization, fast assembly/disassembly operations and assure a sufficient safety level according to typical design provisions of real structures. The results provided in this work show that the proposed technique has been accomplished and a first full-scale prototype has been realized and tested.
\end{abstract}

Keywords: forest mechanisation; forest machine; safety; chainsaw; finite element model.

\section{Introduction}

In the last few decades, the natural disturbances regime of temperate forests in European regions has experienced a remarkable increase [1]. Specifically, a frequency growth of extreme climate events, such as windstorms, has been observed. It is now well known that the occurrence of this kind of disturbances causes widespread damages to forest stands in terms of damaged timber, as it can be seen

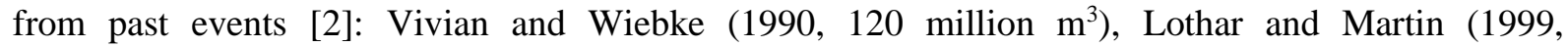
196.7 million $\mathrm{m}^{3}$ ), Gudrun $\left(2005,77.5\right.$ million $\left.\mathrm{m}^{3}\right)$, Kyrill $\left(2007,64.5\right.$ million $\left.\mathrm{m}^{3}\right)$ and Klaus (2009, 44.6 million $\mathrm{m}^{3}$ ). Recently, forest stands in Italian Alpine regions have also been affected by the windstorm Vaia (2018), reporting timber damages for at least 8.5 million $\mathrm{m}^{3}$ [3]. Furthermore, it was found by several authors that such abiotic perturbations tend to be followed by biological diseases, such as bark beetles outbreak [4]. As reported by [5], bark beetles start to proliferate over the large amount of deadwood in the year following the disturbance occurrence. In three years from the windstorm, the insect population can reach such a size that becomes a potential hazard even for still healthy trees, further undermining the profitability of the forest [6].

Considering the aforementioned issues, the post-windthrow management should provide for rapid and efficient salvage logging operations, in order to quickly remove timber from damaged stands and limit the economic loss [7]. Salvage logging implementation is still a matter of debate, since it was reported that it may cause negative impacts on forest communities [8]. By removing the pit-and-mound system created by the windstorm itself, salvage logging disrupts the microsite diversity and consequently it leads to a reduction of biodiversity [9]. Hence, the post-disturbance harvesting should be carefully assessed and planned according to the site-specific conditions [10]. When it can be applied, the most used technical solutions to carried out salvage logging are those based on fully mechanized systems, which decrease the working time and increase the forest worker safety [11]. Nonetheless, when salvage logging operations are conducted in mountain regions, where low density of forest road network and steep terrain conditions limit the application of modern harvesting machines [12], the harvest activities are usually performed through a semi-mechanized system that involves motor-manual felling with chainsaws and log extraction by cable yarders or skidders. In such contest, one of the main problems of harvesting activities is related to the forest workers safety. Indeed, several analyses concerning forestry work accidents have reported that the highest accident and fatality rates occur in clearing damaged tree operations $[13 ; 14]$. This is likely due to the fact that several complex work conditions 
represented by hung-up trees, spars trees and chaotically uprooted trees stacked on top of each other are usually present within a windthrown stand [15]. These situations increase the hazards for the forest workers, mainly because of the internal tensions which collapsed trees are subjected to and that can be suddenly released when approached by feller with chainsaw [16].

In view of this, we can assume that both professional and non-professional forest workers need adequate and specialised training to handle these critical issues. This is also confirmed by the fact that the European Chainsaw Standard (ECS) ranks such logging operations at the highest level of professionalism/complexity (level 4) [17]. Nonetheless, the high-quality training activities needed to develop the competences to cope with complex situations are not easily implementing in real conditions, mainly because of the unsafe environment where training should be conducted. Therefore, a possible solution is realization of a tension simulator that might reproduce the critical conditions of windthrown or damaged trees. Specifically, the simulator should be able to replicate the strong stresses that determine different conditions of traction and compression along the whole stems. The target of this study was the design of a simulator through FEM (Finite Element Model) analysis that could be easily built with standard logs available at the logging site in a controlled and safe environment. The simulator was designed so that it could be applied to logs of different sizes and densities, namely, properties which are strictly depending on tree species available locally and the working context.

\section{Materials and methods}

\section{Concept design and numerical simulations}

A first draft of the simulator was preliminary designed to define the gross dimensions of the simulator. Fig. 1 and Fig. 2 show the front and side view sketches of the assembled simulator. In detail, the structure is composed of: i) two lateral frames that perform as vertical supports for the log to be tested, which is intended to be set in between the two horizontal transoms (Fig. 2); ii) an intermediate frame that serves as contrasting support for the hydraulic jack that will be used to create stress in the tested $\log$ (Fig. 1a); iii) a base of horizontal logs that connects the tree frames while stabilizing them and helps the trainer during the whole loading and cutting operations. All the structure is intended to be realized and assembled with logs available on site. Steel fasteners as screws or steel bars may be used to connect the logs side by side.

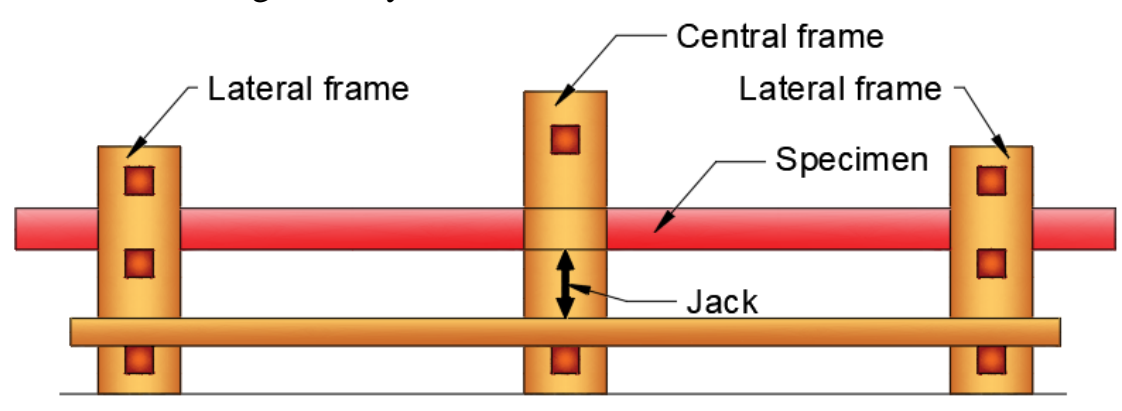

Fig. 1. Front view

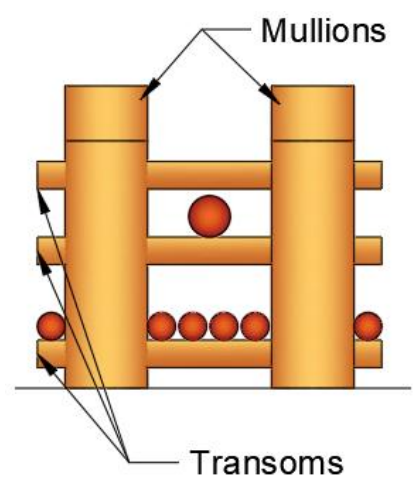

Fig. 2. Side view

Once the overall system was outlined, only the geometrical parameters that would mostly affect the results in terms of the weight, size of the simulator and the stress level of wood were taken into consideration. To this aim, four primary parameters were chosen and varied according to the following values:

- length of the horizontal transoms supporting the logs: 1.5 and $2.0 \mathrm{~m}$;

- spacing between the two lateral frames: 6.0,7.0 and $8.0 \mathrm{~m}$;

- maximum average diameter of the $\log$ to be tested: $0.30,0.40$ and $0.50 \mathrm{~m}$;

- green wood density: 450 and $670 \mathrm{~kg} \cdot \mathrm{m}^{-3}$.

The diameter of the vertical mullions was not included in the parametric analysis, although they might considerably affect the total volume. This is because their size is linked rather to practical and constructive needs (i.e., the minimum thickness necessary to realize the carpentry joints in which the 
horizontal transoms are placed) than to the minimum necessary section deriving from their structural analysis.

\section{Numerical model}

A 3-dimensional finite element model was developed in the general-purpose commercial software Ansys Mechanical Workbench. The geometry was realized in the parametric modeler included in the software. A more refined mesh in the zones where peak stress in the materials was expected, i.e. in proximity of the applied load on the stem to be tested/cut or in the horizontal supports. Fixed restraint conditions were applied to the vertical jambs. A contact formulation algorithm was added to let the stem being supported by the horizontal jambs while being free to rotate. In this way, the static scheme adopted for the stem is equivalent to a simply supported beam with a load applied at the midspan. In order to maintain a suitable precision and performing multiple parametric analyses without excessive computational effort, a total of 15000 brick elements were employed in the model. Modulus of elasticity of green wood was taken from [18]. A load of $80 \mathrm{kN}$ was taken as reference and applied in all the analyses to obtain the maximum stress achievable in both the structure and the log to be cut by applying such force with a portable hydraulic jack.

\section{Results and discussions}

Thirty-six analyses were performed to obtain all the combinations of the four input parameters. From each result, three output parameters were checked in particular:

- weight (or volume) of the structure: to estimate the feasibility in terms of transportation capability in different sites without the need of specific equipment/trucks;

- maximum stress achieved on the horizontal transoms of the supporting frames (Fig. 3): to check the structural safety level of the simulator.

- maximum stress obtained on the $\log$ (Fig. 4): to check the maximum stress that can be obtained on the $\log$ with the $80 \mathrm{kN}$ hydraulic jack.

In all analysed configurations the structure could be retained feasible to support the maximum applied load. Average stress values were contained in the range of 20-25 MPa (Fig. 3). Considering a Modulus of Rupture (MOR) of $36 \mathrm{MPa}$ and $53 \mathrm{MPa}$ for Norway Spruce or Larch, respectively [18], a safety factor of about 1.5 and 2.0 is obtained for the simulator within the analysed range of geometrical parameters.

Fig. 5 shows the simulation of the total weight variation of the modelled structure with respect to the changes in the spacing between the two supporting frames and their width. In detail, the red and green surfaces show the results obtained from the use of Larch or Norway spruce trunks, respectively (mean density of 450 and $670 \mathrm{~kg} \cdot \mathrm{m}^{-3}$ ). Adopting Larch trunks would result in a total weight of the modelled structure between $3125 \mathrm{~kg}$ and $3590 \mathrm{~kg}$ plus $4040 \mathrm{~kg}$ for the horizontal stabilizing logs. Such values would be reduced between 2100 and $2350 \mathrm{~kg}$ plus $2715 \mathrm{~kg}$ with the adoption of Norway Spruce trees.

Fig. 6 shows the variation of the maximum stress (or Modulus of Rupture in the literature) applied on the log within the same combination of geometrical parameters and a load of $80 \mathrm{kN}$. Smaller diameter $\operatorname{logs}(\mathrm{DBH} \leq 0.35 \mathrm{~m})$ could be easily loaded up to high stress levels (thus simulating the worst scenarios). On the opposite, an excessive reduction of spacing $(\leq 0.35 \mathrm{~m})$ would enable the stress levels very far from the MOR for Norway spruce and Larch (dark bluish and light bluish plane in Fig. 6, respectively), thus making the simulator less effective and requiring a stronger pulling force to be applied by the jack.

From the results of the numerical analysis a full-scale prototype of the simulator was realized. It was built with the cooperation of forestry instructors of Lombardy Region (ISFOL), who have extensive experience in training of forest workers, including formative activities related to damaged tree processing. The prototype was developed roughly respecting the element sizes proposed in the conceptual design and by using available logs on the site. The element dimensions are reported in Table 1. 

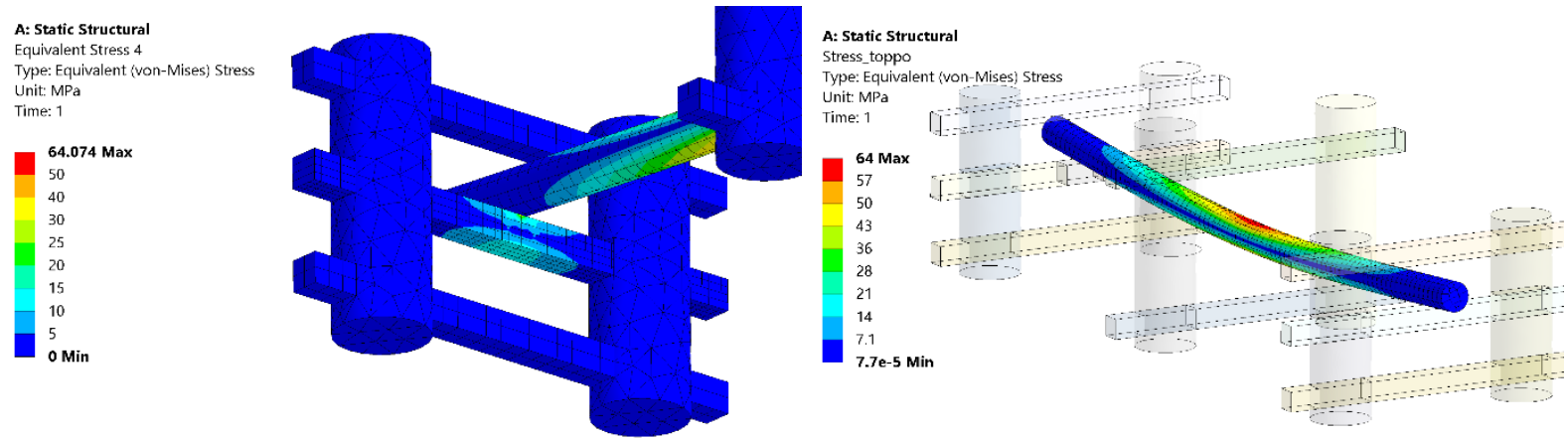

Fig. 3. Stress patterns in the supporting transoms

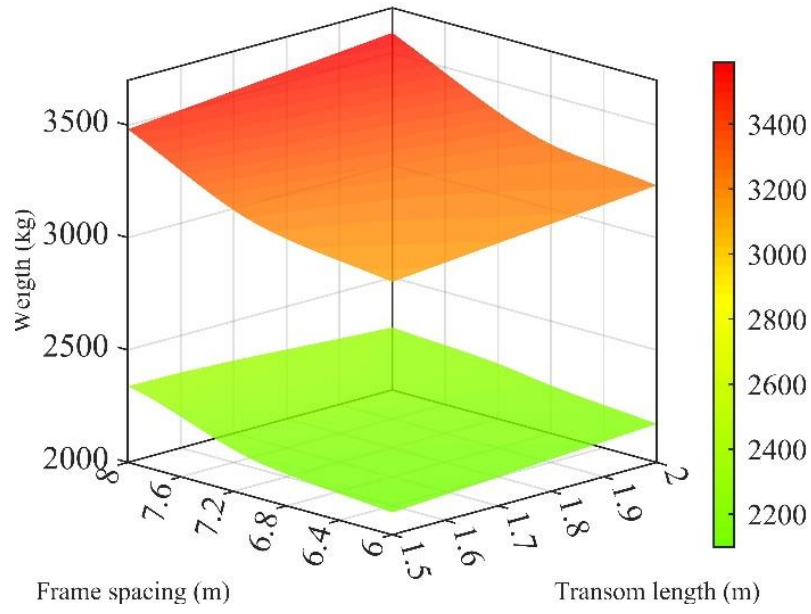

Fig. 4. Stress pattern in the $\log$ to be tested

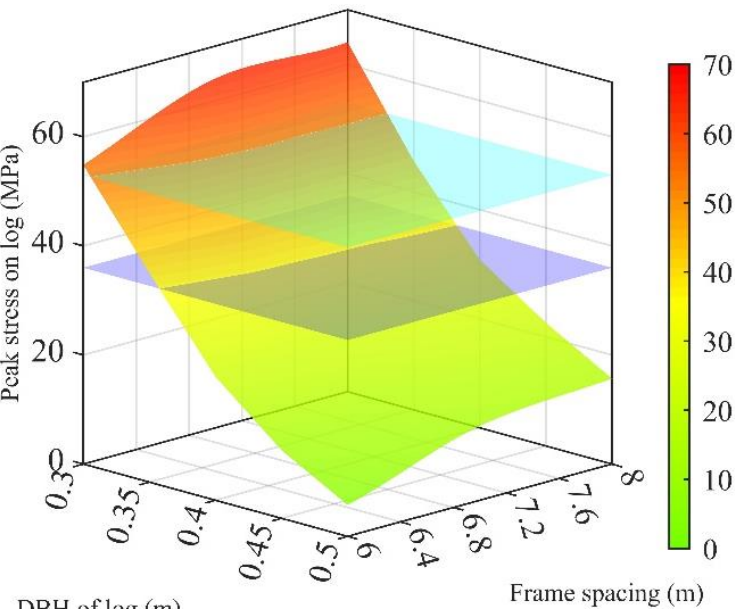

Fig. 5. Weight vs. frame spacing and the transom length

Fig. 6. Peak Stress vs. frame spacing and DBH of the tested log

The mullions were obtained from large Cedar trunks (Cedrus atlantica Endl. Manetti ex Carrière), while the base and the horizontal transoms were made of Larch logs (Larix decidua Mill.). The specimen used to test the prototype was a log of Norway spruce (Picea abies L. H. Karst.). The specimen choice was mainly due to the fact that it was the most affected tree species by windthrow in the Alpine mountain regions during the Vaia windstorm [3]. The three tree species used have the following density values: 440,670 and $450 \mathrm{~kg} \cdot \mathrm{m}^{-3}$ for Cedar, Larch and Norway spruce, respectively [18; 19]. Fig. 7 and Fig. 8 show the final result of the prototype assembly.

Table 1

Prototype element dimensions

\begin{tabular}{|c|c|c|c|c|}
\hline Elements & diameter $-\boldsymbol{\emptyset}, \mathbf{m}$ & height $-\boldsymbol{H}, \mathbf{m}$ & length $-\boldsymbol{L}, \mathbf{m}$ & width $-\boldsymbol{W}, \mathbf{m}$ \\
\hline Mullions (lateral frames) & 0.60 & 1.80 & - & - \\
\hline Mullions (central frames) & 0.60 & 2.20 & - & - \\
\hline Transoms & 0.20 & - & 2.40 & - \\
\hline Base & 0.18 & - & 7.30 & 3.60 \\
\hline Specimen & 0.25 & - & 7.00 & - \\
\hline
\end{tabular}

Following, the functioning of the prototype has been tested. The specimen was put under stress by a hydraulic jack, through which the central area of the log was pushed upward. The central pressure caused an increase in tensile and compressive stresses at the beginning and end areas of the stem, in correspondence with the lateral supports.

This allowed forestry instructors to show the reaction of stressed wood when approached by a chainsaw. When the log was cut at the point of maximum tensile stress, a sudden break in the wood 
fibres occurred with a consequent fast and dangerous movement of the stem processed toward the operator. Afterwards, a second demonstration was carried out, showing that when the cut was performed in correspondence with the maximum compressive stress area, a sudden closure of the log occurred locking the chainsaw bar accordingly. Furthermore, through the simulator the forestry instructors had the possibility to show how a stressed log should be handled, depicting and illustrating the several cut techniques, which can be used in such complex conditions to prevent those critical issues previously experienced.

In agreement with the forestry trainers, we found the performance of the prototype satisfactory. In particular, we observed that the parameters of the numerical model were respected, as no failure occurred in the areas subjected to high stress levels once the prototype was tested (e.g., the horizontal transoms and the specimen). This confirmed the validity of the safety factors predicted by the FEM model. Unfortunately, we were not able to carry out an extensive analysis of the stresses developed as a result of the pressure exerted on the specimen due to the lack of extensometers.

The only technical problem observed was that constructing and assembling the structure resulted to be excessively time consuming. In a real forestry training activity scenario, the implementation of the simulator would require one full day's activity. This would extend the duration of the training event by at least one day compared to the standard time frame. A possible solution could be to consider a resizing of the simulator, so that it can be transported by a truck once it has been realized. In this prospective, the simulator size should be reduced, tacking in account the truck capacity, and therefore limiting the width of the base to $2.50 \mathrm{~m}$. Consequently, a further analysis of the total weight of the structure frame should be performed to carefully plan the loading and unloading phases from the truck. In such way, the time that potentially should be spent to build up the simulator would be saved, allowing to perform the training activity as usual.

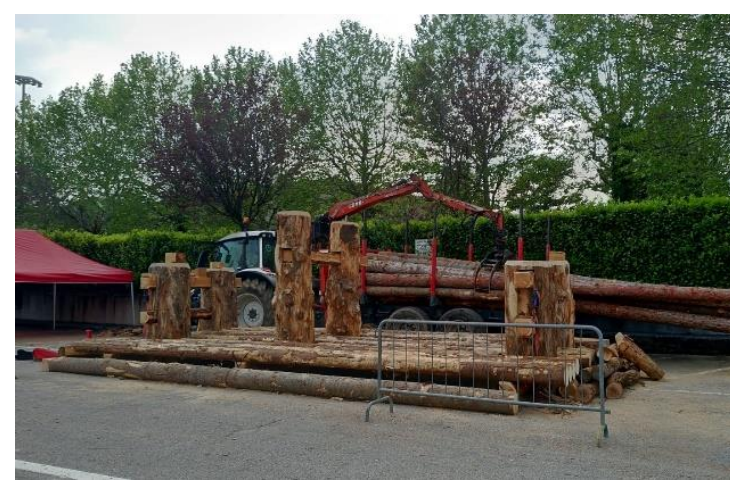

Fig. 7. Full-scale prototype of the simulator

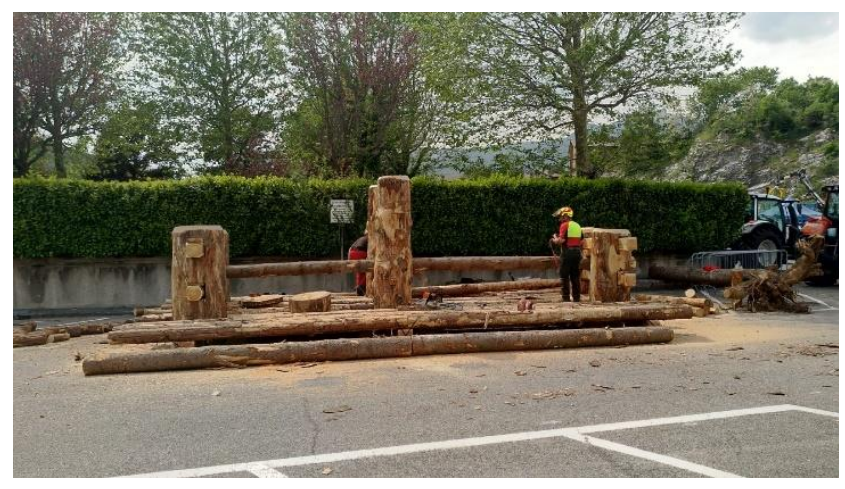

Fig. 8. Full-scale prototype of the simulator with the specimen set

\section{Conclusions}

The preliminary results from the implementation of the prototype have shown that the timber internal stress simulator designed by our study can provide an effective and decisive support for training activities for forest workers, especially those concerning handling of damaged timber. Indeed, it has been proven that the critical issues typically experienced when windthrown trees are approached by forest operators can be faithfully reproduced. This could allow to implement high-quality and specialized training activities in safe and controlled areas, where the several cutting techniques can be taught and performed without any particular difficulties due to the impervious conditions of the environment. Further formative support will subsequently be provided by the forthcoming studies, which will focus on the analysis of the degree of tension that is generated along the whole specimen when the simulator is operated. It is expected that such technical elements will give the trainees a better understanding of the dynamics that occur when dealing with damaged trees. However, the on-site realization of the simulator can take a long time, depending also on the availability of standard logs. It is therefore desirable to resize the entire structure so that it can be transported by a truck once it has been built. In this way, it would be immediately ready for use whenever required and regardless of the location of the training activities. 


\section{Authors' contributions}

Conceptualization F.S, L.M, G.C and S.G..; methodology: L.M., F.S. and S.G.; software, L.M.; validation: F.S. and L.M.; formal analysis, original draft preparation, F.S., L.M. and S.G.; writingreview and editing, S.G.; supervision; all authors have read and agreed to the published version of the manuscript.

\section{Acknowledgments}

Ehe authors acknowledge the Istruttori Forestali Lombardi (ISFOL) for the support to the conceptualization of the work.

\section{Founding}

this work is part of the SafetyForRescue project founded by Regione Lombardia - Bando per il finanziamento di progetti di ricerca in campo agricolo e forestale, d.d.s. 28 marzo 2018 n. 4403.

\section{References}

[1] Gardiner B., Schuck A., Schelhaas M.-J., Orazio C., Blennow K., Nicoll B. Risk management and risk perceptions - understanding the social dimensions in responding to the threat of storm damage. 2013. $132 \mathrm{p}$.

[2] Gardiner B., Blennow K., J. Carnus K. et al. Destructive Storms in European Forests: Past and Forthcoming Impacts. Final Rep. to Eur. Comm. - DG Environ., 2010. 138 p.

[3] Chirici G., Giannetti F., Travaglini D. et al. Forest damage inventory after the 'Vaia' storm in Italy. For. - Riv. di Selvic. ed Ecol. For., vol. 16, no. 1, 2019, pp. 3-9.

[4] Bouget C., Duelli P. The effects of windthrow on forest insect communities: A literature review. Biol. Conserv., vol. 118, no. 3, 2004, pp. 281-299.

[5] Göthlin E., Schroeder L. M., Lindelöw A. Attacks by Ips typographus and Pityogenes chalcographus on Windthrown Spruces (Picea abies) During the Two Years Following a Storm Felling. Scand. J. For. Res., vol. 15, no. 5, 2000, pp. 542-549.

[6] Potterf M., Bone C. Simulating bark beetle population dynamics in response to windthrow events. Ecol. Complex., vol. 32, 2017, pp. 21-30.

[7] Udali A., Andrighetto N., Grigolato S., Gatto P. Economic Impacts of Forest Storms-Taking Stock of After-Vaia Situation of Local Roundwood Markets in Northeastern Italy. Forests, 12(4), 2021, $414 \mathrm{p}$.

[8] Leverkus A. B., Benayas J.R., Castro J. et al. Salvage logging effects on regulating and supporting ecosystem services - A systematic map. Can. J. For. Res., vol. 48, no. 9, 2018, pp. 983-1000.

[9] Waldron K., Ruel J. C., Gauthier, De Grandpré L., Peterson C. J. Effects of post-windthrow salvage logging on microsites, plant composition and regeneration. Appl. Veg. Sci., vol. 17, no. 2, 2014, pp. 323-337.

[10] Bodaghi A. I., Nikooy M., Naghdi R. et al. Ground-based extraction on salvage logging in two high forests: A productivity and cost analysis. Forests, vol. 9, no. 12, 2018, pp. 1-18.

[11] Kärhä K., Anttonen T., Poikela A. et al. Evaluation of salvage logging productivity and costs in windthrown Norway spruce-dominated forests. Forests, vol. 9, no. 5, 2018.

[12] Laschi A., Marchi E., Foderi C., Neri F. Identifying causes, dynamics and consequences of work accidents in forest operations in an alpine context. Saf. Sci., vol. 89, 2016, pp. 28-35.

[13] Garland J. J. Accident reporting and analysis in forestry: guidance on increasing the safety of forest work. 2018. 97 p.

[14] Klun J., Medved M. Fatal accidents in forestry in some European countries. Croat. J. For. Eng., vol. 28, no. 1, , 2007, pp. 55-62.

[15] Sullman M. J. M., Kirk P. M. Harvesting Wind Damaged Trees: A Study of the Safety Implications for Fallers and Choker Setters. Int. J. For. Eng., vol. 12, no. 2, 2001, pp. 67-77.

[16] Bundesverband der Unfallkassen. Gewusst wie - Windwurfaufarbeitung - Wegweiser für den geschulten Anwender (Knowing how - windthrow recovery - guide for the trained user). 1990, No 1. (In German).

[17] EFESC. EUROPEAN CHAINSAW STANDARDS : 2018 ECS 4 : Windblown \& Damaged Tree Techniques, 2018, pp. 1-6. 
[18] Niklas K. J., Spatz H. C. Worldwide correlations of mechanical properties and green wood density. Am. J. Bot., vol. 97, no. 10, 2010, pp. 1587-1594.

[19] Brunetti M., De Capua E., Macchioni N., Monachello S., Natural S. M., De Capua E. L. Natural durability, physical and mechanical properties of Atlas cedar ( Cedrus atlantica Manetti) wood from Southern Italy. 2001. 